\title{
Stability has many names
}

\author{
ZENON MOSZneR
}

Abstract. A list of 22 definitions of stability of a functional equation and 5 definitions of stability of the alternation of two functional equations is given as well as some simple examples.

Mathematics Subject Classification. 39B82, 39B62.

Keywords. Stability, b-stability, Iterative stability, Unique stability, Hyers operator, Superstability, Hyperstability, Inverse stability, Absolute stability, Inverse b-stability, Absolute b-stability, B-stability, Stability of conditional equation, Stabilities of the alternation.

\section{Introduction}

The notion of stability is presently considered in various senses. The original problem of stability was formulated by Ulam in 1940 as follows [22]: "give conditions in order for a linear mapping near an approximately linear mapping to exist".

Ulam has precised the above in different senses. E.g., in [22] he posed the following question.

Let $\mathrm{G}_{1}$ be a group and let $\left(\mathrm{G}_{2}, \mathrm{~d}\right)$ be a metric group. Given $\delta>0$, does there exist $\varepsilon>0$ such that if a mapping $h: G_{1} \rightarrow G_{2}$ satisfies the inequality

$$
\mathrm{d}(\mathrm{h}(\mathrm{xy}), \mathrm{h}(\mathrm{x}) \mathrm{h}(\mathrm{y})) \leq \delta
$$

for all $\mathrm{x}, \mathrm{y} \in \mathrm{G}_{1}$, then there is a homomorphism a $: \mathrm{G}_{1} \rightarrow \mathrm{G}_{2}$ with

$$
\mathrm{d}(\mathrm{h}(\mathrm{x}), \mathrm{a}(\mathrm{x})) \leq \varepsilon
$$

for all $\mathrm{x} \in \mathrm{G}_{1}$ ?

This question yields the subsequent Definition 4 of uniform b-stability.

In [23] Ulam has formulated the question:

Given a metric group $(\mathrm{G}, \mathrm{d})$, a number $\varepsilon>0$ and a mapping $\mathrm{f}: \mathrm{G} \rightarrow \mathrm{G}$ which satisfies the inequality $\mathrm{d}(\mathrm{f}(\mathrm{xy}), \mathrm{f}(\mathrm{x}) \mathrm{f}(\mathrm{y}))<\varepsilon$ for all $\mathrm{x}$, y in $\mathrm{G}$, does there 
exist an automorphism a and a constant $\mathrm{k}>0$, depending only on $\mathrm{G}$, such that $\mathrm{d}(\mathrm{a}(\mathrm{x}), \mathrm{f}(\mathrm{x})) \leq \mathrm{k} \varepsilon$ for all $\mathrm{x}$ in $\mathrm{G}$ ?

This question suggests Definition 5 of strong b-stability.

Hyers formulated in [9] the question of the stability of a homomorphism as follows.

Let $\mathrm{E}$ and $\mathrm{E}$ ' be Banach spaces and let $\delta$ be a positive number. A transformation $\mathrm{f}(\mathrm{x})$ of $E$ into $E$ ' will be called $\delta$-linear if $\|\mathrm{f}(\mathrm{x}+\mathrm{y})-\mathrm{f}(\mathrm{x})-\mathrm{f}(\mathrm{y})\|<\delta$ for all $\mathrm{x}$ and $\mathrm{y}$ in E. Does there exist, for each $\varepsilon>0$, a $\delta>0$ such that to each $\delta$-linear transformation $\mathrm{f}(\mathrm{x})$ there corresponds a linear transformation $\mathrm{l}(\mathrm{x})$ of E into E' satisfying the inequality $\|\mathrm{f}(\mathrm{x})-\mathrm{l}(\mathrm{x})\| \leq \varepsilon$ for all $\mathrm{x}$ in $\mathrm{E}$ ?

Hyers proved in [9] that the answer is positive for $\delta=\varepsilon$ and the function $\mathrm{l}(\mathrm{x})$ is unique. This question suggests our subsequent definitions of the UlamHyers stability and of unique stability.

Remark. In the above Hyers question the inequality for $\mathrm{f}$ is strong $(<\delta)$ and the inequality for $\mathrm{f}$ and $\mathrm{l}$ is weak $(\leq \varepsilon)$. If, in this question, the first inequality is weak $(\leq \delta)$ and the second is strong $(<\varepsilon)$ the result of Hyers with $\delta=\varepsilon$ is not true. Indeed, for $\mathrm{E}=\mathrm{E}^{\prime}=\mathbb{R}$ with the usual metric, the function $\mathrm{f}(\mathrm{x})=\varepsilon$ is such that $|\mathrm{f}(\mathrm{x}+\mathrm{y})-\mathrm{f}(\mathrm{x})-\mathrm{f}(\mathrm{y})| \leq \varepsilon$ and there exists no linear transformation $\mathrm{l}$ for which $|\mathrm{f}(\mathrm{x})-\mathrm{l}(\mathrm{x})|<\varepsilon$ (the bounded linear transformation is the 0-function). If both considered inequalities are strong or both are weak, then the result of Hyers is true.

Hyers and Ulam considered the same kind of stability of isometries in [10].

Since it is impossible to give the general definition of a functional equation, the definitions of stability in Sect. 2 are given for the equation of homomorphism (apart from Definitions 8 and 19). In examples these definitions are transferred to other equations.

Let $\left(\mathrm{G}_{1},+\right)$ be a groupoid and let $\left(\mathrm{G}_{2},+\right)$ be a groupoid with a metric $\mathrm{d}$. We consider the equation

$$
\mathrm{f}(\mathrm{x}+\mathrm{y})=\mathrm{f}(\mathrm{x})+\mathrm{f}(\mathrm{y})
$$

for $\mathrm{f}: \mathrm{G}_{1} \rightarrow \mathrm{G}_{2}$, and the inequalities

$$
\mathrm{d}[\mathrm{g}(\mathrm{x}+\mathrm{y}), \mathrm{g}(\mathrm{x})+\mathrm{g}(\mathrm{y})] \leq \delta \text { for } \mathrm{x}, \mathrm{y} \in \mathrm{G}_{1},
$$

$\mathrm{g}: \mathrm{G}_{1} \rightarrow \mathrm{G}_{2}$ and $\delta>0$, and

$$
\mathrm{d}[\mathrm{g}(\mathrm{x}), \mathrm{f}(\mathrm{x})] \leq \varepsilon \text { for } \mathrm{x} \in \mathrm{G}_{1}
$$

for $\varepsilon>0$.

\section{Stabilities of functional equations}

Definition 1. (Ulam-Hyers stability). The equation (1) is said to be stable in the sense of Ulam-Hyers (shortly "stable") if for every $\varepsilon>0$ there exists a 
$\delta>0$ such that for every function $g: G_{1} \rightarrow G_{2}$ for which (2) is true there exists a solution $\mathrm{f}$ of (1) which satisfies (3).

Example 1. By the classical result of Hyers in [9] Eq. (1) for functions f from a Banach space to a Banach space is stable with $\delta=\varepsilon$. This equation is not stable for $\mathrm{f}$ from a free group $\mathrm{F}$ generated by two elements into $\mathbb{R}[6]$. In fact it is proved in [6] that Eq. (1) in this case is not uniformly b-stable (see Definition 4 below). If in the proof of Theorem 8 in [6] p. 220 we consider the function $\delta f(\delta>0)$ in place of the function $f$ we have the proof that (1) is not stable. Generally if we consider the function $f$ in the equation (1) as a function from the group $\mathrm{F}$ into a subgroup $(\mathrm{G},+) \subset(\mathbb{R},+)$ with the usual metric, then if $\mathrm{G}$ is dense Eq. (1) is unstable and it is not b-stable and in the opposite case this equation is stable and it is not b-stable.

The equation of the idempotent function $\mathrm{f}(\mathrm{f}(\mathrm{x}))=\mathrm{f}(\mathrm{x})$, for $\mathrm{f}$ from a metric space $\mathrm{M}$ with a metric $\mathrm{d}$ into itself, is stable. Indeed, if for a function $\mathrm{g}: M \rightarrow$ $M$ we have $d[g(g(x)), g(x)] \leq \delta$ for $x \in M$, then $f(x)=x$ for $x \in g(M)$ and $f(x)=g(x)$ for $x \in M \backslash g(M)$ is the idempotent function and $d[g(x), f(x)] \leq \delta$ for $\mathrm{x} \in \mathrm{M}$.

The equation $\mathrm{f}(\mathrm{x}+\mathrm{y})=\mathrm{f}(\mathrm{x}) \mathrm{f}(\mathrm{y})$ for $\mathrm{f}: \mathbb{R} \rightarrow(0,+\infty)$ with the usual metric is not stable. Indeed, $\mathrm{f}=1$ is the only bounded solution of this equation and we have for $\varepsilon=\frac{1}{2}, \delta>0$ and $\mathrm{g}(\mathrm{x})=\frac{1}{n}$, that $\frac{1}{n}\left(1-\frac{1}{n}\right) \leq \delta$ and $1-\frac{1}{n}>\varepsilon$ for $\mathrm{n}$ sufficiently large.

Definition 2. (normal stability, strong stability). Equation (1) is said to be normally stable if there exists an unbounded function $\Phi:(0,+\infty) \rightarrow(0,+\infty)$ (measure of stability) such that for every $\varepsilon>0$ and for every function $g$ : $\mathrm{G}_{1} \rightarrow \mathrm{G}_{2}$ for which

$$
\mathrm{d}[\mathrm{g}(\mathrm{x}+\mathrm{y}), \mathrm{g}(\mathrm{x})+\mathrm{g}(\mathrm{y})] \leq \Phi(\varepsilon) \text { for } \mathrm{x}, \mathrm{y} \in \mathrm{G}_{1}
$$

we have (3) for some solution $\mathrm{f}$ of (1).

We say that this stability is strong if there exists a measure of stability of the form $\Phi(\varepsilon)=K \varepsilon$ for some $K$.

Example 2. Equation (1) for $\mathrm{f}$ from an abelian group to a Banach space is normally stable and strongly stable with $\Phi(\varepsilon)=\varepsilon[6]$. In Example 5 there is given a stable equation which is not normally stable. The above equation of the idempotent function is normally and strongly stable with $\Phi(\varepsilon)=\varepsilon$. The equation (1) for $\mathrm{f}$ from a free group generated by two elements into the additive group of integer numbers with the usual metric is stable (every $\delta<1$ is "good") and this stability is not strong since this equation is not b-stable.

Let $\mathrm{I} \subset \mathbb{R}$ be an interval with a non empty interior. The translation equation $\mathrm{F}(\mathrm{F}(\alpha, \mathrm{x}), \mathrm{y})=\mathrm{F}(\alpha, \mathrm{x}+\mathrm{y})$ for $\mathrm{F}: \mathrm{Ix} \mathbb{R} \rightarrow \mathrm{I}$ in the class of functions from Ix $\mathbb{R}$ to I continuous in each variable (i.e. all functions in consideration are in this 
class) is strongly stable with $\delta=\frac{\varepsilon}{10}$ [18]. Moreover, the solution, which is the approximation, is continuous [18].

Remark. The translation equation $\mathrm{F}(\mathrm{F}(\alpha, \mathrm{x}), \mathrm{y})=\mathrm{F}(\alpha, \mathrm{x} \cdot \mathrm{y})$, where $\mathrm{F}: \mathrm{SxG} \rightarrow$ $\mathrm{S}, \mathrm{S}$ is an arbitrary set and $(\mathrm{G},$.$) is a groupoid, is in fact the equation of$ homomorphism of the groupoid $\mathrm{G}$ to the semigroup of the family of functions from $\mathrm{S}$ to $\mathrm{S}$ with the superposition of the functions as the operation. The homomorphism is of the form $\mathrm{x} \rightarrow \mathrm{F}(., \mathrm{x}): \mathrm{S} \rightarrow \mathrm{S}$.

The solution of the translation equation for the interval $S \subset \mathbb{R}$ and $\mathrm{G}=$ $(\mathbb{R},+)$ continuous in each variable is continuous. Indeed, since every solution of the translation equation is a solution of the below inequality for every $\delta>0$, by the above strong stability of the translation equation, every solution of the translation equation continuous in each variable is approximated by a continuous solution. Thus it is continuous too.

The same conclusion is not valid for the solution of the inequality

$$
|\mathrm{H}(\mathrm{H}(\alpha, \mathrm{x}), \mathrm{y})-\mathrm{H}(\alpha, \mathrm{x}+\mathrm{y})| \leq \delta .
$$

In fact, the function $\mathrm{H}(\alpha, \mathrm{x})=\delta \frac{\alpha \mathrm{X}}{\alpha^{2}+\mathrm{x}^{2}}$ for $(\alpha, \mathrm{x}) \neq(0,0)$ and $\mathrm{H}(0,0)=0$ is the solution of the above inequality and it is continuous in each variable but not continuous.

Definition 3. (b-stability). Equation (1) is said to be b-stable if for every function $\mathrm{g}: \mathrm{G}_{1} \rightarrow \mathrm{G}_{2}$ the function $\mathrm{d}[\mathrm{g}(\mathrm{x}+\mathrm{y}), \mathrm{g}(\mathrm{x})+\mathrm{g}(\mathrm{y})]$ is bounded, then the function $d[g(x), f(x)]$ is bounded for some solution $f$ of $(1)$.

Example 3. Equation (1), if the groupoids $\mathrm{G}_{1}$ and $\mathrm{G}_{2}$ are Banach spaces, is bstable. The equation of homomorphism $\mathrm{f}(\mathrm{x}+\mathrm{y})=\mathrm{f}(\mathrm{x}) \mathrm{f}(\mathrm{y})$, for $\mathrm{f}: \mathbb{R} \rightarrow(0,+\infty)$, is b-stable [1]. This equation is an example of an equation which is b-stable and unstable. The translation equation $\mathrm{F}(\mathrm{F}(\alpha, \mathrm{x}), \mathrm{y})=\mathrm{F}(\alpha, \mathrm{xy})$, for $\mathrm{F}: \mathrm{ZxG} \rightarrow \mathrm{Z}$, where $\mathrm{Z}$ is the set of integer numbers with the usual metric and $\mathrm{G}$ is a free group generated by two elements, is not b-stable [15].

Definition 4. (uniform b-stability). Equation (1) is said to be uniformly bstable if for every $\delta>0$ there exists an $\varepsilon>0$ such that for every g: $\mathrm{G}_{1} \rightarrow \mathrm{G}_{2}$ for which (2) is true there exists a solution $\mathrm{f}$ of (1) which satisfies (3).

Example 4. Equation (1), where $\mathrm{G}_{1}$ is an abelian group and $\mathrm{G}_{2}$ is a Banach space, is uniformly b-stable with $\varepsilon=\delta$. A functional equation which is not b-stable is evidently not uniformly b-stable. The normally uniformly b-stable functional equations below (Example 5) are obviously uniformly b-stable.

Remark. The uniform b-stability is uniform since $\varepsilon$ does not depend on the function g. The Ulam-Hyers stability is in fact already uniform since in Definition 1 the number $\delta$ does not depend on the function g. Every equation is non-uniformly stable, i.e., "for $\varepsilon>0$ and a function $g$ there exists $\delta>0 \ldots$ " $[17]$. 
Definition 5. (normal uniform b-stability, strong b-stability). Equation (1) is said to be normally uniformly b-stable if there exists a function $\Psi:(0,+\infty) \rightarrow$ $(0,+\infty)$ (measure of uniform b-stability) for which inf $\Psi((0,+\infty))=0$ and such that for every $\delta>0$ and $\mathrm{g}: \mathrm{G}_{1} \rightarrow \mathrm{G}_{2}$ for which (2) is true,

$$
\mathrm{d}[\mathrm{g}(\mathrm{x}), \mathrm{f}(\mathrm{x})] \leq \Psi(\delta) \text { for } \mathrm{x} \in \mathrm{G}_{1}
$$

is satisfied for some solution $\mathrm{f}$ of $(1)$.

If there exists a measure of uniform b-stability of the form $\Psi(\delta)=\mathrm{K} \delta$ for some $\mathrm{K}$, then the b-stability is called strong.

Example 5. Equation (1), if $\mathrm{G}_{1}$ and $\mathrm{G}_{2}$ are Banach spaces, is normally uniformly b-stable with $\Psi(\delta)=\delta$. Equation (4) is not normally uniformly b-stable. The equation $\mathrm{f}(\mathrm{x}+\mathrm{y})=\mathrm{f}(\mathrm{x}) \mathrm{f}(\mathrm{y})$ for $\mathrm{f}: \mathbb{R} \rightarrow(0,+\infty)$ with the usual metric is bstable and it is not strongly b-stable since this equation is not stable. The equation $\mathrm{f}^{2}(2 \mathrm{x})=4 \mathrm{f}^{2}(\mathrm{x})$, for $\mathrm{f}: \mathbb{R} \rightarrow \mathbb{R}$, is normally uniformly b-stable with $\Psi(\delta)=\sqrt{\frac{\delta}{3}}[15]$ and stable $\left(\Phi(\varepsilon)=3 \varepsilon^{2}\right)$ but it is not strongly b-stable. Indeed, assume that there exists a $K$ such that for every $\delta>0$ and every function $\mathrm{g}: \mathbb{R} \rightarrow \mathbb{R}$ if $\left|\mathrm{g}^{2}(2 \mathrm{x})-4 \mathrm{~g}^{2}(\mathrm{x})\right| \leq \delta$, then there exists a solution $\mathrm{f}$ of the equation such that $|g(x)-f(x)| \leq K \delta$. For the function $g(x)=\sqrt{\frac{\delta}{3}}$ we have $\left|\mathrm{g}^{2}(2 \mathrm{x})-4 \mathrm{~g}^{2}(\mathrm{x})\right| \leq \delta$, thus there exists a solution $\mathrm{f}$ of our equation such that $|g(x)-f(x)| \leq K \delta$. Since the function $g$ is bounded, the solution $\mathrm{f}$ is bounded too, thus $\mathrm{f}=0\left(\mathrm{f}^{2}(\mathrm{x})=4^{-\mathrm{n}} \mathrm{f}\left(2^{\mathrm{n}} \mathrm{x}\right)\right)$. We have $\sqrt{\frac{\delta}{3}} \leq \mathrm{K} \delta$ and for $\delta=\frac{1}{4 K^{2}}$ we obtain a contradiction.

The situation is the same for the equation $[f(x+y)]^{2}=[f(x)+f(y)]^{2}$ for $f$ : $\mathbb{R} \rightarrow \mathbb{R}[15]$.

Definition 6. (restricted b-stability, restricted uniform b-stability). Equation (1) is restrictedly uniformly b-stable if there exists a $\delta_{0}>0$ such that for every $\delta>0$ and $\delta<\delta_{0}$ and for every $\mathrm{g}: \mathrm{G}_{1} \rightarrow \mathrm{G}_{2}$ for which (2) is true there exist an $\varepsilon>0$ and a solution $\mathrm{f}$ of (1) which satisfies (3). If $\varepsilon$ does not depend on the function $g$ in (2) this restricted b-stability is said to be uniform. The measure of restricted uniform b-stbility is defined here as the function $\Psi:\left(0, \delta_{0}\right) \rightarrow$ $(0,+\infty)$. This restricted uniform b-stability is normal if there exists a measure $\Psi$ such that inf $\Psi\left(\left(0, \delta_{0}\right)\right)=0$.

Example 6. Every equation (normally) uniformly b-stable is evidently (normally) restrictedly uniformly b-stable.

The equation

$$
|\mathrm{f}(\mathrm{f}(\mathrm{x}))-\mathrm{f}(\mathrm{x})|+\left|\frac{f(x)-f(y)}{x-y}-1\right|=0
$$

for $\mathrm{f}: \mathbb{R} \rightarrow \mathbb{R}$, has $\mathrm{f}(\mathrm{x})=\mathrm{x}$ as the only solution and it is restrictedly uniformly b-stable and not b-stable. Indeed, for $y=0$ we have $f(x)=x+f(0)$ and from 
$\mathrm{f}(\mathrm{f}(\mathrm{x}))=\mathrm{f}(\mathrm{x})$ we obtain $\mathrm{f}(0)=0$. Moreover for $\mathrm{g}(\mathrm{x})=0$ the function $\lg (\mathrm{g}(x))-$ $\mathrm{g}(x)|+| \frac{\mathrm{g}(\mathrm{x})-\mathrm{g}(\mathrm{y})}{\mathrm{x}-\mathrm{y}}-1 \mid$ is bounded and the function $|0-\mathrm{x}|$ is unbounded, thus Eq. (4) is not b-stable.

Assume that

$$
|\mathrm{g}(\mathrm{g}(\mathrm{x}))-\mathrm{g}(\mathrm{x})|+\left|\frac{g(x)-g(y)}{x-y}-1\right| \leq \delta
$$

for a function $g: \mathbb{R} \rightarrow \mathbb{R}$ and $0<\delta<1$. Therefore

$$
|g(\mathrm{~g}(\mathrm{x}))-\mathrm{g}(\mathrm{x})| \leq \delta \text { and }\left|\frac{g(x)-g(y)}{x-y}-1\right| \leq \delta .
$$

Thus

$$
0<1-\delta \leq \frac{g(x)-g(y)}{x-y} \leq 1+\delta,
$$

the function $g$ is thus strictly increasing. Let $y \in \mathbb{R}$ be arbitrarily fixed. Since $\mathrm{g}$ is increasing, there exists $\lim _{\mathrm{x} \rightarrow \mathrm{y}-0} \mathrm{~g}(\mathrm{x}) \leq \mathrm{g}(\mathrm{y})$. For $\lim _{\mathrm{x} \rightarrow \mathrm{y}-0} \mathrm{~g}(\mathrm{x})<\mathrm{g}(\mathrm{y})$, we have

$$
\lim _{\mathrm{x} \rightarrow \mathrm{y}-0} \frac{g(x)-g(\mathrm{y})}{\mathrm{x}-\mathrm{y}}=+\infty,
$$

thus a contradiction to (5). Therefore $\lim _{\mathrm{x} \rightarrow \mathrm{y}-0} \mathrm{~g}(\mathrm{x})=\mathrm{g}(\mathrm{y})$ and analogously $\lim _{x \rightarrow y+0} g(x)=g(y)$. The function $g$ is thus continuous. This function is unbounded from above and from below. For the indirect proof assume that $\mathrm{g}$ is bounded from above. The sequence $\mathrm{g}(\mathrm{n})$ is increasing and bounded in this case, thus there exists $\operatorname{limg}(\mathrm{n})$. We have $\lim \frac{g(n+1)-g(n)}{(n+1)-n}=0$, thus a contradiction to (5). The function $\mathrm{g}$ is thus unbounded from above. We have, by analogous proof, that $\mathrm{g}$ is unbounded from below. Since $\mathrm{g}$ is continuous we obtain that $\mathrm{g}(\mathbb{R})=\mathbb{R}$. Thus for every $\mathrm{x} \in \mathbb{R}$ there exists a $\mathrm{y}$ such that $\mathrm{g}(\mathrm{y})=\mathrm{x}$ and we have $|\mathrm{g}(\mathrm{x})-\mathrm{x}|=|\mathrm{g}(\mathrm{g}(\mathrm{y}))-\mathrm{g}(\mathrm{y})| \leq \delta$. Our equation is thus restrictedly uniformly b-stable. It is also stable since for every $\varepsilon>0$ every positive number $\delta<1$ is "good" for the stability. This stability is not normal since normal stability implies b-stability [17].

Definition 7. (unique stability). Equation (1) is called uniquely stable (uniquely normally stable, uniquely uniformly b-stable, uniquely normally uniformly bstable, uniquely restrictedly uniformly b-stable) if the solution of (1) in (3) or in (3') is unique.

Example 7. Hyers in [9] proved that Eq. (1) is uniquely stable. The translation equation for functions from $\mathrm{I} \times \mathbb{R}$ to $\mathbb{R}$ is stable in the class of continuous functions and this stability is not unique [18].

Remark. The uniqueness of the stability of Eq. (1) allows us to study the properties of the Hyers operator which assigns the solution $\mathrm{f}$ of (1), which satisfies (3), to the function $g$ so that (2) is satisfied [14]. 
Definition 8. (iterative stability). Let $\mathrm{S}$ be an arbitrary set and $\mathrm{M}$ be a metric space with metric d. Let $\mathrm{k}, \mathrm{l}$ be functions from $\mathrm{SxS}$ to $\mathrm{S}$ and $\mathrm{F}, \mathrm{K}$ be the functions from SxSxMxMxMxM to M. We define for $\mathrm{g}: \mathrm{S} \rightarrow \mathrm{M}$

$$
\begin{aligned}
\mathrm{k}_{1}(\mathrm{x}, \mathrm{y}) & =\mathrm{k}(\mathrm{x}, \mathrm{y}), \mathrm{k}_{\mathrm{n}+1}(\mathrm{x}, \mathrm{y})=\mathrm{k}\left[\mathrm{k}_{\mathrm{n}}(\mathrm{x}, \mathrm{y}), \mathrm{y}\right] \text { for } \mathrm{n} \in \mathrm{N}, \\
\mathrm{F}_{1}(\mathrm{x}, \mathrm{y}, \mathrm{g}) & =\mathrm{F}[\mathrm{x}, \mathrm{y}, \mathrm{g}(\mathrm{x}), \mathrm{g}(\mathrm{y}), \mathrm{g}(\mathrm{k}(\mathrm{x}, \mathrm{y})), \mathrm{g}(\mathrm{l}(\mathrm{x}, \mathrm{y}))] \\
\mathrm{F}_{\mathrm{n}+1}(\mathrm{x}, \mathrm{y}, \mathrm{g}) & =\mathrm{F}\left[\mathrm{k}_{\mathrm{n}}(\mathrm{x}, \mathrm{y}), \mathrm{y}, \mathrm{F}_{\mathrm{n}}(\mathrm{x}, \mathrm{y}, \mathrm{g}), \mathrm{g}(\mathrm{y}), \mathrm{g}\left(\mathrm{k}_{\mathrm{n}+1}(\mathrm{x}, \mathrm{y})\right), \mathrm{g}(\mathrm{l}(\mathrm{x}, \mathrm{y}))\right] \\
& \quad \text { for } \mathrm{n} \in \mathrm{N}
\end{aligned}
$$

and functions $\mathrm{K}_{\mathrm{n}}$ analogously.

The functional equation

$F[x, y, f(x), f(y), f(k(x, y)), f(l(x, y))]=K[x, y, f(x), f(y), f(k(x, y)), f(l(x, y))]$ is said to be iteratively stable if for every $\varepsilon>0$ there exists a $\delta>0$ such that for every function $\mathrm{g}: \mathrm{S} \rightarrow \mathrm{M}$ for which

$$
\mathrm{d}\left[\mathrm{F}_{n}(\mathrm{x}, \mathrm{y}, \mathrm{g}), \mathrm{K}_{\mathrm{n}}(\mathrm{x}, \mathrm{y}, \mathrm{g})\right] \leq \delta \text { for } \mathrm{x}, \mathrm{y} \in \mathrm{S} \text { and } \mathrm{n} \in \mathrm{N}
$$

there exists a solution $\mathrm{f}$ of the equation such that $\mathrm{d}[\mathrm{g}(\mathrm{x}), \mathrm{f}(\mathrm{x})] \leq \varepsilon$ for $\mathrm{x} \in \mathrm{S}$.

If there exists a constant $\mathrm{L}$ such that $\delta=\mathrm{L} \varepsilon$, then this stability is called strong.

Example 8. The equation

$$
f(\alpha(x))=\beta(x) f(x)+\gamma(x),
$$

where $\alpha, \beta, \gamma$ are countinuous functions from an interval $I$ to $\mathbb{R}$ and $\mathrm{f}$ is the unknown function, is strongly iteratively stable in the class of continuous functions under an adequate hypothesis [4]. The equation $f(x+c)=f(x)$ for the periodic function is not stable and it is iteratively stable.

Definition 9. (superstability). Equation (1) is said to be superstable if every function $\mathrm{g}: \mathrm{G}_{1} \rightarrow \mathrm{G}_{2}$ for which the function $\mathrm{d}[\mathrm{g}(\mathrm{x}+\mathrm{y}), \mathrm{g}(\mathrm{x})+\mathrm{g}(\mathrm{y})]$ is bounded, is the solution of (1) or it is bounded.

Remark. The term "superstability" is not "good" since a superstable equation may be unstable. E.g., the equation $f(x+y)=f(x) f(y)$ for $f: \mathbb{R} \rightarrow(0,+\infty)$ with the usual metric is superstable ([1]; the first paper on the theme of superstability) and it is not stable (see Example 1).

Example 9. Equation (1) for $\mathrm{f}: \mathbb{R} \rightarrow \mathbb{R}$ is evidently not superstable (for $\mathrm{g}(\mathrm{x})=$ $\mathrm{x}+\delta$ the function $\mathrm{g}(\mathrm{x}+\mathrm{y})-\mathrm{g}(\mathrm{x})-\mathrm{g}(\mathrm{y})$ is bounded and $\mathrm{g}$ is neither bounded nor additive)-see Example 11 too.

Definition 10. (uniform superstability). Equation (1) is uniformly superstable if it is superstable and the family of the bounded solutions of the inequality (2) is uniformly bounded. 
Example 10. The equation in the above remark is uniformly superstable since we have $|\mathrm{g}(\mathrm{x})| \leq \max (4,4 \delta)$ for bounded solutions of the inequality $\mid \mathrm{g}(\mathrm{x}+\mathrm{y})-$ $\mathrm{g}(\mathrm{x}) \mathrm{g}(\mathrm{y}) \mid \leq \delta$. The sine functional equation

$$
\mathrm{f}(\mathrm{x}+\mathrm{y}) \mathrm{f}(\mathrm{x}-\mathrm{y})=\mathrm{f}^{2}(\mathrm{x})-\mathrm{f}^{2}(\mathrm{y})
$$

for $\mathrm{f}$ from an abelian group uniquely divisible by 2 to $\mathrm{C}$, is superstable and it is not uniformly superstable [5].

Definition 11. (hyperstability). Equation (1) is said to be hyperstable if every function $\mathrm{g}: \mathrm{G}_{1} \rightarrow \mathrm{G}_{2}$ for which the function $\mathrm{d}[\mathrm{g}(\mathrm{x}+\mathrm{y}), \mathrm{g}(\mathrm{x})+\mathrm{g}(\mathrm{y})]$ is bounded, is the solution of (1).

Example 11. If every function $\mathrm{f}: \mathrm{G}_{1} \rightarrow \mathrm{G}_{2}$ is a homomorphism, then Eq. (1) is evidently hyperstable. Also if, e.g., $\mathrm{x}+\mathrm{y}=\mathrm{x}$ for every $\mathrm{x}, \mathrm{y} \in \mathrm{G}_{1}$ and for every $\mathrm{x}, \mathrm{y} \in \mathrm{G}_{2}$.

The equation

$$
|\mathrm{f}(\mathrm{x}+\mathrm{y})-\mathrm{f}(\mathrm{x})-\mathrm{f}(\mathrm{y})|+|\mathrm{f}(\mathrm{xy})-\mathrm{f}(\mathrm{x}) \mathrm{f}(\mathrm{y})|=0
$$

for $\mathrm{f}$ from a normed algebra to a complete normed algebra, is hyperstable [3]. The derivation equation

$$
f(x y)=y f(x)+x f(y)
$$

where $\mathrm{f}: \mathrm{A} \rightarrow \mathrm{B}(\mathrm{E})$ and $\mathrm{E}$ is a Banach space, $\mathrm{A}$ is an algebra of operators on $\mathrm{E}$, $\mathrm{B}(\mathrm{E})$ is the algebra of bounded operators on $\mathrm{E}$, is hyperstable (the corollary from the theorem in the paper [20]). The sine equation (see Example 10) is superstable and not hyperstable $(\mathrm{g}(\mathrm{x})=\sqrt{\delta}$ is the solution of the inequality $\left|g(x+y) g(x-y)-g^{2}(x)+g^{2}(y)\right| \leq \delta$ and it is not the solution of the sine equation).

Analogously to Ulam's problem one may pose the following one: Is a function, which is approximated by a solution of a functional equation, an approximate solution of this equation? More exactly

Definition 12. (inverse stability). Equation (1) is said to be inversely stable if for every $\delta>0$ there exists a $\varepsilon>0$ such that for every function $g: G_{1} \rightarrow G_{2}$ if (3) is true for a solution $\mathrm{f}$ of (1), then $\mathrm{g}$ satisfies (2).

Example 12. The equation of homomorphism $\mathrm{f}(\mathrm{xy})=\mathrm{f}(\mathrm{x}) \mathrm{f}(\mathrm{y})$ for $\mathrm{f}$ from a groupoid to a metric groupoid, is inversely stable with $\varepsilon=\delta / 3$ [14]. The equation $f(x+y)=f(x) f(y)$ for $f$ from $\mathbb{R}$ to $\mathbb{R}$, is not inversely stable (for $g(x)=$ $\operatorname{expx}+\delta$ we have $|\mathrm{g}(\mathrm{x})-\operatorname{expx}| \leq \delta$ and the function $\mathrm{g}(\mathrm{x}+\mathrm{y})-\mathrm{g}(\mathrm{x}) \mathrm{g}(\mathrm{y})$ is unbounded).

Definition 13. (absolute stability). Equation (1) is said to be absolutely stable if it is stable and inversely stable.

Example 13. The equation of homomorphism from an abelian group to a Banach space is absolutely inversely stable. 
Remark. Stability and inverse stability are independent. Indeed, the homomorphism equation from a free group generated by two elements to $\mathbb{R}$ is inversely stable and it is not stable. The equation of the idempotent function $f(f(x))=f(x)$ for $\mathrm{f}$ from a metric space into itself is stable and it is not inversely stable [14].

Definition 14. (inverse b-stability). Equation (1) is said to be inversely b-stable if for every function $\mathrm{g}: \mathrm{G}_{1} \rightarrow \mathrm{G}_{2}$ for which there exists a solution $\mathrm{f}$ of (1) such that the function $d[g(x), f(x)]$ is bounded, the function $d[g(x+y), g(x)+g(y)]$ is also bounded.

Example 14. The equation $\mathrm{f}^{2}(\mathrm{x})=\mathrm{f}^{2}(0)$, where $\mathrm{f}: \mathbb{R} \rightarrow \mathbb{R}$, is inversely b-stable and it is not inversely stable [14]. The equation $[\mathrm{f}(\mathrm{x})]^{-1}=1$ for $\mathrm{f}: \mathbb{R} \rightarrow \mathbb{R}$, is not inversely b-stable and it is inversely stable [14].

Definition 15. (absolute b-stability). Equation (1) is said to be absolutely bstable if it is b-stable and inversely b-stable.

Example 15. The equations (1) and $\mathrm{f}(\mathrm{x})=1$ for $\mathrm{f}: \mathbb{R} \rightarrow \mathbb{R}$ are evidently absolutely b-stable.

Definition 16. (inverse uniform b-stability). Equation (1) is inversely uniformly b-stable if for every $\varepsilon>0$ there exists a $\delta>0$ such that for every g : $\mathrm{G}_{1} \rightarrow \mathrm{G}_{2}$ for which (3) is true for a solution $\mathrm{f}$ of (1), g satisfies (2).

Example 16. The equation (1) is evidently inversely uniformly b-stable $(\delta=$ $3 \varepsilon)$. The first equation in Example 14 is not inversely uniformly b-stable [14].

Definition 17. (absolute uniform b-stability). Equation (1) is said to be absolutely uniformly b-stable if it is uniformly b-stable and inversely uniformly b-stable.

Example 17. as in Example 16.

The b-stability is generalised in [7] in the following way. Let $\mathrm{G}_{2}$ be a group in which there is defined a family $\mathbf{B}$ of subsets of $G_{2}$ such that

(a) $\mathbf{B}$ contains all singletons,

(b) $\mathrm{A}+\mathrm{B} \in \mathbf{B}$ for $\mathrm{A}, \mathrm{B} \in \mathbf{B}$,

(c) $-\mathrm{A} \in \mathbf{B}$ for $\mathrm{A} \in \mathbf{B}$.

A set in $\mathbf{B}$ is called B-bounded and functions whose range is in $\mathbf{B}$ are called B-bounded.

Definition 18. (B-stability). We say that Eq. (1) is B-stable if for every function $\mathrm{g}: \mathrm{G}_{1} \rightarrow \mathrm{G}_{2}$ for which the function $\mathrm{g}(\mathrm{x}+\mathrm{y})-\mathrm{g}(\mathrm{x})-\mathrm{g}(\mathrm{y})$ is B-bounded there exists a solution $f$ of $(1)$ such that the function $g(x)-f(x)$ is B-bounded.

Uniform B-stability (for every B-bounded set A there exists a set B in B such that ...) B-superstability etc. are defined analogously (see also [13]).

Example 18. By the result of Hyers the equation of homomorphism is Bstable for $G_{1}=G_{2}=(\mathbb{R},+)$ and the usual boundedness in $G_{2}$ as the Bboundedness. If $\mathrm{G}_{1}=\mathrm{G}_{2}=(\mathrm{Q},+)$ and for the usual boundedness in $\mathrm{G}_{2}$ as 
the B-boundedness the equation of homomorphism is not B-stable (an indirect proof by the function $\mathrm{g}: \mathrm{Q} \rightarrow \mathrm{Q}$ such that the function $\mathrm{g}(\mathrm{x})-\sqrt{2} \mathrm{x}$ is bounded $[13])$.

The equation of homomorphism from a groupoid $\mathrm{G}_{1}$ to the abelian group $\mathrm{G}_{2}$ is B-stable for every family $\mathbf{B}$ of B-bounded sets in $\mathrm{G}_{2}$, i.e., for every set $A \in \mathbf{B}$ there exists a set $B \in \mathbf{B}$ such that for every function $\mathrm{g}: \mathrm{G}_{1} \rightarrow \mathrm{G}_{2}$ if $\mathrm{g}(\mathrm{x}+\mathrm{y})-\mathrm{g}(\mathrm{x})-\mathrm{g}(\mathrm{y}) \in \mathrm{B}$ for $\mathrm{x}, \mathrm{y} \in \mathrm{G}_{1}$, there exists a homomorphism $\mathrm{f}: \mathrm{G}_{1} \rightarrow \mathrm{G}_{2}$ for which $g(x)-f(x) \in A$ for $x$ in $G_{1}$. Indeed, for $A=\emptyset$ it is sufficient to put $\mathrm{B}=\emptyset$. If $\mathrm{A} \neq \emptyset$, let $\mathrm{a} \in \mathrm{A}$. Assume that $\mathrm{g}(\mathrm{x}+\mathrm{y})-\mathrm{g}(\mathrm{x})-\mathrm{g}(\mathrm{y}) \in\{-a\}$ for $\mathrm{x}, \mathrm{y} \in \mathrm{G}_{1}$. Then the function $\mathrm{f}(\mathrm{x})=\mathrm{g}(\mathrm{x})$-a is the homomorphism from $\mathrm{G}_{1}$ to $\mathrm{G}_{2}$ and $\mathrm{g}(\mathrm{x})-\mathrm{f}(\mathrm{x})=\mathrm{a} \in \mathrm{A}$ for every $\mathrm{x}$ in $\mathrm{G}_{1}$.

Definition 19. (stability of conditional equation). Let $F(x, y)$ for $\mathrm{x}, \mathrm{y}$ in $\mathrm{G}_{1}$ be a sentential function. The conditional functional equation

$$
F(x, y) \Rightarrow \mathrm{f}(\mathrm{x}+\mathrm{y})=\mathrm{f}(\mathrm{x})+\mathrm{f}(\mathrm{y})
$$

is called stable if for every $\varepsilon>0$ there exists $\delta>0$ such that for every function $\mathrm{g}: \mathrm{G}_{1} \rightarrow \mathrm{G}_{2}$ for which

$$
F(x, y) \Rightarrow|\mathrm{g}(\mathrm{x}+\mathrm{y})-\mathrm{g}(\mathrm{x})-\mathrm{g}(\mathrm{y})| \leq \delta \text { for } \mathrm{x}, \mathrm{y} \in \mathrm{G}_{1}
$$

there is a function $\mathrm{f}: \mathrm{G}_{1} \rightarrow \mathrm{G}_{2}$ such that

$$
F(x, y) \Rightarrow \mathrm{f}(\mathrm{x}+\mathrm{y})=\mathrm{f}(\mathrm{x})+\mathrm{f}(\mathrm{y}) \text { for } \mathrm{x}, \mathrm{y} \in \mathrm{G}_{1}
$$

and $|\mathrm{g}(\mathrm{x})-\mathrm{f}(\mathrm{x})| \leq \varepsilon$ for $\mathrm{x}$ in $\mathrm{G}_{1}$.

Example 19. Equation (4) is in fact a conditional functional equation with $F(x, y)=(\mathrm{x} \neq \mathrm{y})$.

The conditional equation

$$
\left.\mathrm{x}_{-}\right|_{-} \mathbf{y} \Rightarrow \mathrm{f}(\mathrm{x}+\mathrm{y})=\mathrm{f}(\mathrm{x})+\mathrm{f}(\mathrm{y})
$$

if $\mathrm{f}$ is a mapping from an orthogonality space onto a real Banach space, is stable with $\delta=\frac{3}{16} \varepsilon[8]$.

Let $\mathrm{X}$ and $\mathrm{Y}$ be a real normed space and a real Banach space, respectively. Let $\mathrm{d}>0$ be a given real number. The conditional equation

$$
|\mathrm{x}|+|\mathrm{y}| \geq \mathrm{d} \Rightarrow|f(0)|+\left|2 \mathrm{f}\left(\frac{x+y}{2}\right)-\mathrm{f}(\mathrm{x})-\mathrm{f}(\mathrm{y})\right|=0
$$

for $\mathrm{f}: \mathrm{X} \rightarrow \mathrm{Y}$, is stable with $\delta=\frac{\varepsilon}{6}[11]$.

Remark. We consider the stability of the conditional functional equation in which the condition depends on the unknown function. E.g, we have the following result [3].

Let $(\mathrm{S},+)$ be an Abelian semigroup and let $(\mathrm{X},||$.$) be a Banach space. If,$ for some $\varepsilon_{1}, \varepsilon_{2} \geq 0$ and all $\mathrm{x}, \mathrm{y} \in \mathrm{S}$, a function $\mathrm{f}: \mathrm{S} \rightarrow \mathrm{X}$ satisfies

$$
|f(x+y)+f(x)+f(y)|>\varepsilon_{1} \Rightarrow|f(x+y)-f(x)-f(y)| \leq \varepsilon_{2},
$$


then there exists a unique additive function $\mathrm{a}: \mathrm{S} \rightarrow \mathrm{X}$ such that

$$
|\mathrm{f}(\mathrm{x})-\mathrm{a}(\mathrm{x})| \leq \max \left\{\varepsilon_{1}, \varepsilon_{2}\right\} \text { for } \mathrm{x} \in \mathrm{S} .
$$

This result is in fact the result of stability for the alternation

$$
\mathrm{f}(\mathrm{x}+\mathrm{y})+\mathrm{f}(\mathrm{x})+\mathrm{f}(\mathrm{y}) \mid=0 \text { or } \mathrm{f}(\mathrm{x}+\mathrm{y})-\mathrm{f}(\mathrm{x})-\mathrm{f}(\mathrm{y})=0
$$

of the equations $f(x+y)+f(x)+f(y) \mid=0$ and $f(x+y)-f(x)-f(y)=0$ (see Sect. 3).

\subsection{Examples of relations between these stabilities}

We have here all possibilities.

1. Strong stability and strong b-stability are equivalent.

2. Normal stability implies uniform b-stability and the normal uniform b-stability implies normal stability but not conversely [17].

3. Stability and b-stability are independent, i.e., stability does not imply b-stability and vice versa. Stability implies the restricted b-stability but not conversely. This implication is not true for restricted uniform b-stability.

4. B-stability and the conditional stability are generalizations of stability.

\subsection{Examples of the dynamical system}

A dynamical system is defined as a continuous solution $\mathrm{F}: \mathrm{Ix} \mathbb{R} \rightarrow \mathrm{I}$, where $\mathrm{I}$ is an interval in $\mathbb{R}$ with a nonempty interior, of the equation

$$
|\mathrm{F}(\mathrm{F}(\mathrm{x}, \mathrm{t}), \mathrm{s})-\mathrm{F}(\mathrm{x}, \mathrm{t}+\mathrm{s})|+|\mathrm{F}(\mathrm{x}, 0)-\mathrm{x}|=0 .
$$

This definition is equvalent to the one: a dynamical system is a solution $\mathrm{F}: \mathrm{Ix} \mathbb{R} \rightarrow \mathrm{I}$ of the equation

$$
|\mathrm{F}(\mathrm{F}(\mathrm{x}, \mathrm{t}), \mathrm{s})-\mathrm{F}(\mathrm{x}, \mathrm{t}+\mathrm{s})|+\left|\mathrm{F}^{\prime}(\mathrm{x}, 0)-1\right|=0,
$$

where $\mathrm{F}^{\prime}(\mathrm{x}, 0)$ means the derivative of the function $\mathrm{F}(., 0): I \rightarrow \mathrm{I}$ at the point $\mathrm{x}$.

Equation (6) in the class of continuous functions from $\mathrm{Ix} \mathbb{R}$ to $\mathrm{I}$ is (see [16])

- $\quad$ stable (normally, strongly) only for $I=\mathbb{R}$,

- b-stable (normally, strongly), uniformly b-stable and restrictedly uniformly b-stable (normally) only for I being bounded or $I=\mathbb{R}$,

- inversely b-stable, absolutely b-stable, inversely uniformly b-stable, absolutely uniformly b-stable, superstable, uniformly superstable and inversely superstable only for I bounded,

- inversely stable, absolutely stable and hyperstable for no I,

- $\quad$ inversely hyperstable for every I. 
Equation (7) in the class of continuous functions from Ix $\mathbb{R}$ to $\mathrm{I}$ is (see [16] and [17])

- stable, restrictively uniformly b-stable (normally) and inversely hyperstable for every I,

- normally stable, b-stable ${ }^{1}$, uniformly b-stable (normally), superstable and uniformly superstable only for I being bounded,

- $\quad$ inversely stable, absolutely stable, inversely b-stable, absolutely b-stable, inversely uniformly b-stable, absolutely uniformly b-stable, inversely superstable and hyperstable for no I.

Remark. The stability of Eq. (7) is not strong for the interval I unbouded. Indeed, assume there is a $\mathrm{K}>0$ such that for every $\varepsilon>0$ and for every function $\mathrm{G}: \mathrm{Ix} \mathbb{R} \rightarrow \mathrm{I}$ if

$$
|\mathrm{G}(\mathrm{G}(\mathrm{x}, \mathrm{t}), \mathrm{s})-\mathrm{G}(\mathrm{x}, \mathrm{t}+\mathrm{s})|+\left|\mathrm{G}^{\prime}(\mathrm{x}, 0)-\mathrm{x}\right| \leq \mathrm{K} \varepsilon \text { for } \mathrm{x} \in \mathrm{I}, \mathrm{t}, \mathrm{s} \in \mathbb{R},
$$

then there exists a solution $F$ of (7) such that $|\mathrm{G}(\mathrm{x}, \mathrm{t})-\mathrm{F}(\mathrm{x}, \mathrm{t})| \leq \varepsilon$ for $(\mathrm{x}, \mathrm{t}) \in \mathrm{Ix} \mathbb{R}$. We have a contradiction since for $\varepsilon=\mathrm{K}^{-1}$ and $\mathrm{G}(\mathrm{x}, \mathrm{t})=\mathrm{c} \in \mathrm{I}$ the function $|\mathrm{G}(\mathrm{x}, 0)-\mathrm{F}(\mathrm{x}, 0)|=|\mathrm{c}-\mathrm{x}|$ is unbounded for $\mathrm{x} \in \mathrm{I}$. For a bounded I this stability is strong with e.g. $\mathrm{K}=\min \left\{\frac{1}{10}, \frac{2}{5|\mathrm{I}|}\right\}$ by the Corollary 3.8 in [15] and by the fact that $\left|\mathrm{F}_{1}(\mathrm{x}, \mathrm{t})-\mathrm{F}_{2}(\mathrm{x}, \mathrm{t})\right| \leq|\mathrm{I}|$ for all functions $\mathrm{F}_{1}, \mathrm{~F}_{2}: \mathrm{Ix} \mathbb{R} \rightarrow \mathrm{I}$. The situation is the same for b-stability.

Remark. The inequalities

$$
|\mathrm{H}(\mathrm{H}(\mathrm{x}, \mathrm{t}), \mathrm{s})-\mathrm{H}(\mathrm{x}, \mathrm{t}+\mathrm{s})|+|\mathrm{H}(\mathrm{x}, 0)-\mathrm{x}| \leq \delta \text { for }(\mathrm{x}, \mathrm{t}) \in \operatorname{Ix} \mathbb{R}
$$

and

$$
|\mathrm{H}(\mathrm{H}(\mathrm{x}, \mathrm{t}), \mathrm{s})-\mathrm{H}(\mathrm{x}, \mathrm{t}+\mathrm{s})|+\left|\mathrm{H}^{\prime}(\mathrm{x}, 0)-1\right| \leq \delta \text { for }(\mathrm{x}, \mathrm{t}) \in \mathrm{Ix} \mathbb{R}
$$

are equivalent for $\delta=0$. For $\delta>0$ the inequality (8) does not imply the inequality (9) (example: $\mathrm{H}(\mathrm{x}, \mathrm{t})=\mathrm{h}(\mathrm{x})$, where the non-differentiable function $\mathrm{h}: \mathrm{I} \rightarrow \mathrm{I}$ is such that $\left.|\mathrm{h}(\mathrm{x})-\mathrm{x}| \leq \frac{\delta}{2}\right)$. For $\delta \geq 1$ and I unbounded or $\delta<|\mathrm{I}|$ the inequality (9) does not imply the inequality (8) (example: $\mathrm{H}(\mathrm{x}, \mathrm{t})=\mathrm{c}$ for $\mathrm{c} \in \mathrm{I}$ such that $\left.\sup _{\mathrm{x} \in \mathrm{I}}|x-c|>\delta\right)$. For $\delta \geq|\mathrm{I}|$ the inequality (8) is true with $2 \delta$ since $|\mathrm{H}(\mathrm{H}(\mathrm{x}, \mathrm{t}), \mathrm{s})-\mathrm{H}(\mathrm{x}, \mathrm{t}+\mathrm{s})| \leq \delta$ and $|\mathrm{H}(\mathrm{x}, 0)-\mathrm{x}| \leq \delta$ in this case. For $\delta<1$ the inequality (9) implies the inequality (8) with $\frac{3 \delta}{1-\delta}$ in place of $\delta$ (by an analogous proof as the one of Corollary 3.8 in [16] we have $\left.|\mathrm{H}(\mathrm{x}, 0)-\mathrm{x}| \leq \frac{2+\delta}{1-\delta} \delta\right)$.

Remark. The Ulam-Hyers-Rassias stability is also considered when $\varepsilon$ and $\delta$ in the above definitions are replaced by more general functionals. For example in [19] we have the theorem.

\footnotetext{
${ }^{1}$ In the table at the end of the paper [16] is my mistake: the Eq. (7) (def.2 in the table) is not b-stable for every interval I, it is b-stable only for bounded I - for the details see [17]. Moreover the function $\mathrm{F}$ in the def. 4 in this table must be non-constant.
} 
Let $\mathrm{E}_{1}$ and $\mathrm{E}_{2}$ be Banach spaces. If $\mathrm{f}: \mathrm{E}_{1} \rightarrow \mathrm{E}_{2}$ satisfies the inequality

$$
\|f(x+y)-f(x)-f(y)\| \leq Q\left(\|x\|^{p}+\|y\|^{p}\right), x, y \in E_{1}
$$

for some $\mathrm{Q} \geq 0$ and some $0 \leq \mathrm{p}<1$, then there exists a unique additive mapping $\mathrm{A}: \mathrm{E}_{1} \rightarrow \mathrm{E}_{2}$ such that

$$
\|\mathrm{f}(\mathrm{x})-\mathrm{A}(\mathrm{x})\| \leq 2 \mathrm{Q}\left(2-2^{\mathrm{p}}\right)^{-1}\|\mathrm{x}\|^{\mathrm{p}}, \mathrm{x} \in \mathrm{E}_{1} .
$$

\section{Stability of the alternation of two functional equations}

Below we consider, in the real case, the relation betwen different stabilities of the alternation " $\left(\mathrm{E}_{1}\right)$ or $\left(\mathrm{E}_{2}\right)$ " of two functional equations $\left(\mathrm{E}_{1}\right)$ and $\left(\mathrm{E}_{2}\right)$ and the stability of these equations. This alternation is in fact the implication "not $\left(\mathrm{E}_{1}\right) \Rightarrow\left(\mathrm{E}_{2}\right)$ ", i.e., it is the conditional functional equation.

Let $\mathrm{E}_{i}(\mathrm{f})=0$ for $\mathrm{i}=1,2, \ldots$ be functional equations of one real variable $\mathrm{x}$ (described also as $\mathrm{E}_{i}(\mathrm{f})(\mathrm{x})=0$ ) and $\mathrm{f}: \mathbb{R} \rightarrow \mathrm{D} \subset \mathbb{R}$.

Definition 20. (boundedness of the alternation). The alternation

$$
\mathrm{E}_{1}(\mathrm{f})=0 \text { or } \mathrm{E}_{2}(\mathrm{f})=0
$$

is called bounded for the function $\mathrm{g}: \mathbb{R} \rightarrow \mathrm{D} \subset \mathbb{R}$ if there exists a $\delta>0$ such that

$$
\left|\mathrm{E}_{1}(\mathrm{~g})\right| \leq \delta \text { or }\left|\mathrm{E}_{2}(\mathrm{~g})\right| \leq \delta \text { for } \mathrm{x} \in \mathbb{R} .
$$

In this case the alternation (10) is said to be "bounded by $\delta$ ".

Definition 21. (stability of the alternation of functional equations). The alternation (10) is called Ulam-Hyers stable (in short: stable) if for every $\varepsilon>0$ there exists $\delta>0$ such that for every function $\mathrm{g}: \mathbb{R} \rightarrow \mathrm{D} \subset \mathbb{R}$ for which this alternation is bounded by $\delta$, there exists a solution $\mathrm{f}$ of the alternation (10) such that $|\mathrm{g}(\mathrm{x})-\mathrm{f}(\mathrm{x})| \leq \varepsilon$ for $\mathrm{x} \in \mathbb{R}$.

Theorem 1. (a) The alternation of two stable equations may be unstable.

(b) The alternation of two unstable equations may be stable.

(c) The alternation of two equations for which the first is stable and the second unstable may be unstable (stable).

Proof. (a) The equations $|\mathrm{f}(\mathrm{x})|-\mathrm{x}=0$ and $|\mathrm{f}(\mathrm{x})|+\mathrm{x}=0$ for $\mathrm{f}: \mathbb{R} \rightarrow \mathbb{R} \backslash\{0\}$ are stable since for $\delta>0$ there exists no solution of the inequality || $\mathrm{g}(\mathrm{x})|-\mathrm{x}| \leq \delta$ for $\mathrm{x} \in \mathbb{R}$, e.g., for $\mathrm{x}<0$, and there exists no solution of the inequality || $\mathrm{g}(\mathrm{x})|+x| \leq \delta$ for $\mathrm{x} \in \mathbb{R}$, e.g., for $\mathrm{x}>0$. On the other hand, there exists a solution of the alternation " || $\mathrm{g}(\mathrm{x})|-\mathrm{x}| \leq \delta$ or || $\mathrm{g}(\mathrm{x})|+\mathrm{x}| \leq \delta$, e.g., $\mathrm{g}(\mathrm{x})=\mathrm{x}$ for $\mathrm{x} \neq 0$ and $\mathrm{g}(0)=\delta$ and the alternation $"|\mathrm{f}(\mathrm{x})|=\mathrm{x}$ or $|\mathrm{f}(\mathrm{x})|=-\mathrm{x}$ " has no solution (putting $\mathrm{x}=0$ we have a contradiction). Thus the last alternation is not stable. 
(b) The equation $\mathrm{f}(\mathrm{x}) \mathrm{f}(1) \mathrm{x}=0$ for $\mathrm{f}: \mathbb{R} \rightarrow \mathbb{R} \backslash\{0\}$ is unstable since it has no solution $(\mathrm{x}=0)$ and the inequality $|\mathrm{g}(\mathrm{x})-\mathrm{g}(1) \mathrm{x}| \leq \delta$ has a solution for every $\delta>0$ (e.g., $\mathrm{g}(\mathrm{x})=\mathrm{ax}$ for some $\mathrm{a} \neq 0$ and $\mathrm{x} \neq 0$ and $\mathrm{g}(0)=\delta$ ). Analogically, the equation $\mathrm{f}(\mathrm{x})=\mathrm{f}(0)(1-\mathrm{x})$ is not stable. On the other hand, the alternation of these equations is stable. For a $\delta>0$ assume that the function $g: \mathbb{R} \rightarrow \mathbb{R} \backslash\{0\}$ is such that

$$
|g(x)-g(1) \mathrm{x}| \leq \delta \quad \text { or } \quad|g(x)-g(0)(1-x)| \leq \delta .
$$

Let $\mathrm{A}:=\{\mathrm{x} \in \mathbb{R}: \mid \mathrm{g}(\mathrm{x})-\mathrm{g}(1) \mathrm{x} \in \leq \delta\}$ and $\mathrm{B}:=\{\mathrm{x} \in \mathbb{R}: \mid \mathrm{g}(\mathrm{x})-\mathrm{g}(0)(1-$ $\mathrm{x}) \mid \leq \delta\}$; thus for every $\mathrm{x} \in \mathbb{R}: \mathrm{x} \in \mathrm{A}$ or $\mathrm{x} \in \mathrm{B}$. We define the function $\mathrm{f}: \mathbb{R} \rightarrow \mathbb{R} \backslash\{0\}$ as follows

1. for $x \in A: f(0)=g(0)$ if $0 \in A$ and $f(x)=g(1) x$ for $x \neq 0$,

2. for $x \in B \backslash A: f(1)=g(1)$ if $1 \in B \backslash A$ and $f(x)=g(0)(1-x)$ for $x \neq 1$.

This function is a solution of the alternation

$$
\mathrm{f}(\mathrm{x})-\mathrm{f}(1) \mathrm{x}=0 \text { or } \mathrm{f}(\mathrm{x})-\mathrm{f}(0)(1-\mathrm{x})=0
$$

since $f(0)=g(0)$ and $f(1)=g(1)$, thus this alternation has the form

$$
\mathrm{f}(\mathrm{x})-\mathrm{g}(1) \mathrm{x}=0 \text { or } \mathrm{f}(\mathrm{x})-\mathrm{g}(0)(1-\mathrm{x})=0 .
$$

Moreover, evidently $|\mathrm{g}(\mathrm{x})-\mathrm{f}(\mathrm{x})| \leq \delta$.

(c) For the equations $\mathrm{f}(\mathrm{x})-2=0$ and $\mathrm{f}(\mathrm{x})-\mathrm{x}=0$ for $\mathrm{f}: \mathbb{R} \rightarrow \mathbb{R} \backslash\{0\}$, the first one is stable, the second one is unstable and their alternation is unstable. Assume, for the indirect proof, that this alternation is stable. Thus for $\varepsilon=1$ there exists $\delta>0$ such that for every function $\mathrm{g}: \mathbb{R} \rightarrow \mathbb{R} \backslash\{0\}$ such that $|\mathrm{g}(\mathrm{x})-2| \leq \delta$ or $\lg (\mathrm{x})-\mathrm{x} \in \leq \delta$ there exists a solution $\mathrm{f}$ of the considered alternation such that $|\mathrm{g}(\mathrm{x})-\mathrm{f}(\mathrm{x})| \leq 1$ for $\mathrm{x} \in \mathbb{R}$.. Let $\mathrm{n} \in \mathrm{N}$ be such that $\delta / \mathrm{n}<1$. For $\mathrm{g}(\mathrm{x})=\mathrm{x}$ if $\mathrm{x} \neq 0$ and $\mathrm{g}(0)=\delta / \mathrm{n}$ we have $|\mathrm{g}(\mathrm{x})-\mathrm{x}| \leq \delta$ for $\mathrm{x} \in \mathbb{R}$, thus the alternation $"|g(x)-2| \leq \delta$ or $|g(x)-\mathrm{x}| \leq \delta$ " is true. There exists a solution $\mathrm{f}$ of the alternation " $\mathrm{f}(\mathrm{x})=2$ or $\mathrm{f}(\mathrm{x})=\mathrm{x}$ " such that $|\mathrm{g}(\mathrm{x})-\mathrm{f}(\mathrm{x})| \leq 1$. We have $\mathrm{f}(0)=2$ since $\mathrm{f}(0)=0$ is impossible, thus $|\mathrm{g}(0)-\mathrm{f}(0)|=|\delta / \mathrm{n}-2|=2-\delta / \mathrm{n} \leq 1$. We obtain $1 \leq \delta / \mathrm{n}$, thus a contradiction to $\delta / \mathrm{n}<1$.

For the equations $f(x)-f(x)=0$ and $f(x)-f(1) x=0$ for $f: \mathbb{R} \rightarrow \mathbb{R} \backslash\{0\}$, the first is evidently stable, the second is not stable (see (b)) and their alternation is evidently stable.

Since the alternation of the same two stable (unstable) equations is evidently stable (ustable) we have

Conclusion 1. There is no relation between the stability of the functional equations and the stability of their alternation.

Remark. Every alternation (10) is not-uniformly stable in the sense that "for $\varepsilon>0$ and for every function $g$ there exists $\delta>0 \ldots$. Indeed, if $\mathrm{g}$ is a solution 
of the alternation, then every $\delta>0$ is "good". If $\mathrm{g}$ is not a solution of the alternation, then there exists an $\mathrm{x}_{0} \in \mathrm{S}$ such that

$$
\mathrm{E}_{1}(\mathrm{~g})\left(\mathrm{x}_{0}\right) \neq 0 \text { and } \mathrm{E}_{2}(\mathrm{~g})\left(\mathrm{x}_{0}\right) \neq 0 \text {. }
$$

In this case $\delta<\min \left\{\left|\mathrm{E}_{1}(\mathrm{~g})\left(\mathrm{x}_{0}\right)\right|,\left|\mathrm{E}_{2}(\mathrm{~g})\left(\mathrm{x}_{0}\right)\right|\right\}$ is "good".

Definition 22. (b-stability and the uniform b-stability of the alternation). The alternation (10) is called b-stable if for every function $g: \mathbb{R} \rightarrow \mathrm{D} \subset \mathbb{R}$ for which this alternation is bounded there exists a solution $\mathrm{f}$ of this alternation (10) such that $|g(x)-f(x)|$ is bounded. The b-stability is called uniform if the constant which bounds $|g(x)-f(x)|$ depends not on the function g, i.e., if for every $\delta>0$ there exsits an $\varepsilon>0$ such that for every function $g: \mathbb{R} \rightarrow \mathrm{D} \subset \mathbb{R}$ for which (11) for $x \in \mathbb{R}$ is satisfied, there exists a solution $f$ of (10) such that $|\mathrm{g}(\mathrm{x})-\mathrm{f}(\mathrm{x})| \leq \varepsilon$ for $\mathrm{x} \in \mathbb{R}$.

Definition 23. (inverse stability of the alternation). The alternation (10) is called inversely stable if for every $\varepsilon>0$ there exsits $\delta>0$ such that for every function $\mathrm{g}: \mathbb{R} \rightarrow \mathrm{D} \subset \mathbb{R}$ for which there exists a solution $\mathrm{f}$ of (10) such that $|g(x)-f(x)| \leq \delta$ for $x \in \mathbb{R}$, we have $\left|E_{1}(g)\right| \leq \varepsilon$ or $\left|E_{2}(g)\right| \leq \varepsilon$ for $x \in \mathbb{R}$.

Definition 24. (inverse b-stability of the alternation). The alternation (10) is said to be inversely b-stable if for every function $\mathrm{g}$ the boundedness of the function $|g(x)-f(x)|$ for a solution $f$ of (10) implies (11) for some $\delta>0$.

The inverse uniform b-stability, absolute stability, absolute b-stability, superstability, inverse superstability, absolute superstability for the alternation of two functional equations are defined analogously as for a single functional equation.

Remark. For the above stabilities there is the same situation as in Conclusion 1 except for inverse superstability.

We have here

Theorem 2. If in the alternation of two equations at least one is inversely superstable, then this alternation is inversely superstable, too.

Proof. If the function $\mathrm{g}$ is the solution of the alternation, then the alternation for this function $\mathrm{g}$ is evidently bounded. If $\mathrm{g}$ is bounded and $\mathrm{E}(\mathrm{f})=0$ is the equation in the alternation which is inversely superstable, then $\mathrm{E}(\mathrm{g})$ is bounded, thus the alternation for the function $g$ is bounded too.

Remark. The alternation (10) is equivalent to the product equation

$$
\mathrm{E}_{1}(\mathrm{f}) \mathrm{E}_{2}(\mathrm{f})=0 .
$$

The inequality

$$
\left|\mathrm{E}_{1}(\mathrm{f})(\mathrm{x}) \mathrm{E}_{2}(\mathrm{f})(\mathrm{x})\right| \leq \delta^{2} \text { for } \mathrm{x} \in \mathbb{R}
$$


implies

$$
\left.\forall \mathrm{x} \in \mathbb{R}\left\{\mid \mathrm{E}_{1}(\mathrm{f})(\mathrm{x})\right) \mid \leq \delta \text { or }\left|\mathrm{E}_{2}(\mathrm{f})(\mathrm{x})\right| \leq \delta\right\}
$$

Therefore, the stability of the alternation (10) implies the stability of the product equation (12).

The converse implication is not true. E.g., the product $f(x))[f(x)]^{-1}=0$ is stable for $\mathrm{f}: \mathbb{R} \rightarrow \mathbb{R} \backslash\{0\}$. Indeed, the inequality $\mid \mathrm{g}(\mathrm{x}))[\mathrm{g}(\mathrm{x})]^{-1} \mid \leq \delta$ has no solution for $\delta<1$. The alternation $\mathrm{f}(\mathrm{x})=0$ or $[\mathrm{f}(\mathrm{x})]^{-1}=0$ is unstable since it has no solution and for every $\delta>0$ we have for every function $\mathrm{g}(\mathrm{x}): \mathbb{R} \rightarrow(0, \delta)$ that $|\mathrm{g}(\mathrm{x})| \leq \delta$ or $\left|[\mathrm{g}(\mathrm{x})]^{-1}\right| \leq \delta$ for every $\mathrm{x} \in \mathbb{R}$.

The condition (11) does not imply the condition (13). E.g., for the equations $\mathrm{f}(2 \mathrm{x})-2 \mathrm{f}(\mathrm{x})=0$ and $\mathrm{f}(2 \mathrm{x})=0$, for $\mathrm{f}: \mathbb{R} \rightarrow \mathbb{R}$, and the function $\mathrm{f}(\mathrm{x})=\mathrm{x}+\delta$ the condition (11) is satisfied and the condition (13) is not.

A consideration of the functional equations without the solutions is not very interesting (but it is perhaps simpler) therefore the following problem arises.

Problem. Improve the above example and examples in the proof of Theorem 1 replacing those functional equations which do not have solutions by equations having their solutions.

The condition (11) is equivalent to the condition

$$
\forall \mathrm{x} \in \mathbb{R}\left\{\mathrm{E}_{1}(\mathrm{f})(\mathrm{x})|>\delta=>| \mathrm{E}_{2}(\mathrm{f})(\mathrm{x}) \mid \leq \delta\right\} .
$$

\section{Acknowledgements}

I wish to thank the referee for a number of valuable remarks.

Open Access. This article is distributed under the terms of the Creative Commons Attribution 4.0 International License (http://creativecommons.org/licenses/by/4.0/), which permits unrestricted use, distribution, and reproduction in any medium, provided you give appropriate credit to the original author(s) and the source, provide a link to the Creative Commons license, and indicate if changes were made.

\section{References}

[1] Baker, J.A., Lawrence, J., Zorzitto, F.: The stability of the equation $f(x+y)=$ $f(x) f(y)$. Proc. Am. Math. Soc. 74, 242-246 (1979)

[2] Batko, B.: On the stability of an alternative functional equation. Math. Inequal. Appl. 8(4), 685-691 (2005)

[3] Bourgin, D.G.: Approximately isometric and multiplicative transformations on continuous function rings. Duke Math. J. 16, 385-397 (1949)

[4] Brydak, D.: On the stability of the functional equation $\varphi[\mathrm{f}(\mathrm{x})]=\mathrm{g}(\mathrm{x}) \varphi(x)+\mathrm{F}(\mathrm{x})$. Proc. Am. Math. Soc. 26, 455-460 (1970)

[5] Cholewa, P.W.: The stability of sine equation. Proc. Am. Math. Soc. 88, 631-634 (1983) 
[6] Forti, G.L.: The stability of homomorphisms and amenability, with applications to functional equations. Abh. Math. Semin. Univ. Hamburg 57, 215-226 (1987)

[7] Ger, R.: Abstract boundedness and the stability of Pexider equation. Pr. Nauk. Wyż. Szk. Pedagog. Czestochowa Mat. 9, 41-49 (2003)

[8] Ger, R., Sikorska, J.: Stability of the orthogonal additivity. Bull. Polish Acad. Sci. Math. 43, 143-151 (1995)

[9] Hyers, D.H.: On the stability of the linear functional equation. Proc. Nat. Acad. Sci. USA 27, 222-224 (1941)

[10] Hyers, D.H., Ulam, S.M.: On approximate isometries. Bull. Am. Math.Soc. 51, 288$292(1945)$

[11] Yung, S.M.: Hyers-Ulam-Rassias stability of Jensen's equation and its application. Proc. Am. Math. Soc. 126(11), 3137-3143 (1998)

[12] Moszner, Z.: Les opérateurs de Hyers. In: Daróczy, Z., Palés, Z. (eds.) Functional Equations-Results and Advances. pp. 113-122. Kluwer Academic Publishers (2002)

[13] Moszner, Z.: On the stability of functional equations. Aeq. Math. 77, 33-88 (2009)

[14] Moszner, Z.: On the inverse stability of the functional equations. Banach Center Pub. 99, 111-121 (2013)

[15] Moszner, Z.: On the stability of the squares of some functional equations. Ann. Univ. Paedag. Cracoviensis. Studia Math. 14, 81-104 (2015)

[16] Moszner, Z., Przebieracz, B.: Is the dynamical system stable?. Aeq. Math. 89(2), 279296 (2015)

[17] Moszner, Z.: On the normal stability of functional equations. Ann. Math. Silesianae. doi:10.1515/amsil-2016-0001

[18] Przebieracz, B.: On the stability of the translation equation and dynamical systems. Nonlinear Anal. 75(4), 1980-1988 (2012)

[19] Rassias, T.M.: On the stability of the linear mapping in Banach spaces. Proc. Am. Math. Soc. 72(2), 297-300 (1978)

[20] Šemrl, P.: The functional equation of multiplicative derivation is superstable on standard operator algebras. Integral Equ. Operator Theory 18, 118-122 (1994)

[21] Singleton, B.D.: The life and work of D.H. Hyers, 1913-1997. In: Nonlinear Functional Analysis and Applications, vol. 11, No. 5, pp. 697-732. Library Faculty Publications (2006)

[22] Ulam, S.M.: A collection of Mathematical Problems. Interscience Publ., New York (1960)

[23] Ulam, S.M.: Problems in Modern Mathematics. Wiley, New York (1964)

Zenon Moszner

Institute of Mathematics

Pedagogical University

Podchorażych 2

30-084 Kraków

Poland

e-mail: zmoszner@up.krakow.pl

Received: January 20, 2016

Revised: June 20, 2016 